
Not for reproduction, distribution or commercial use.

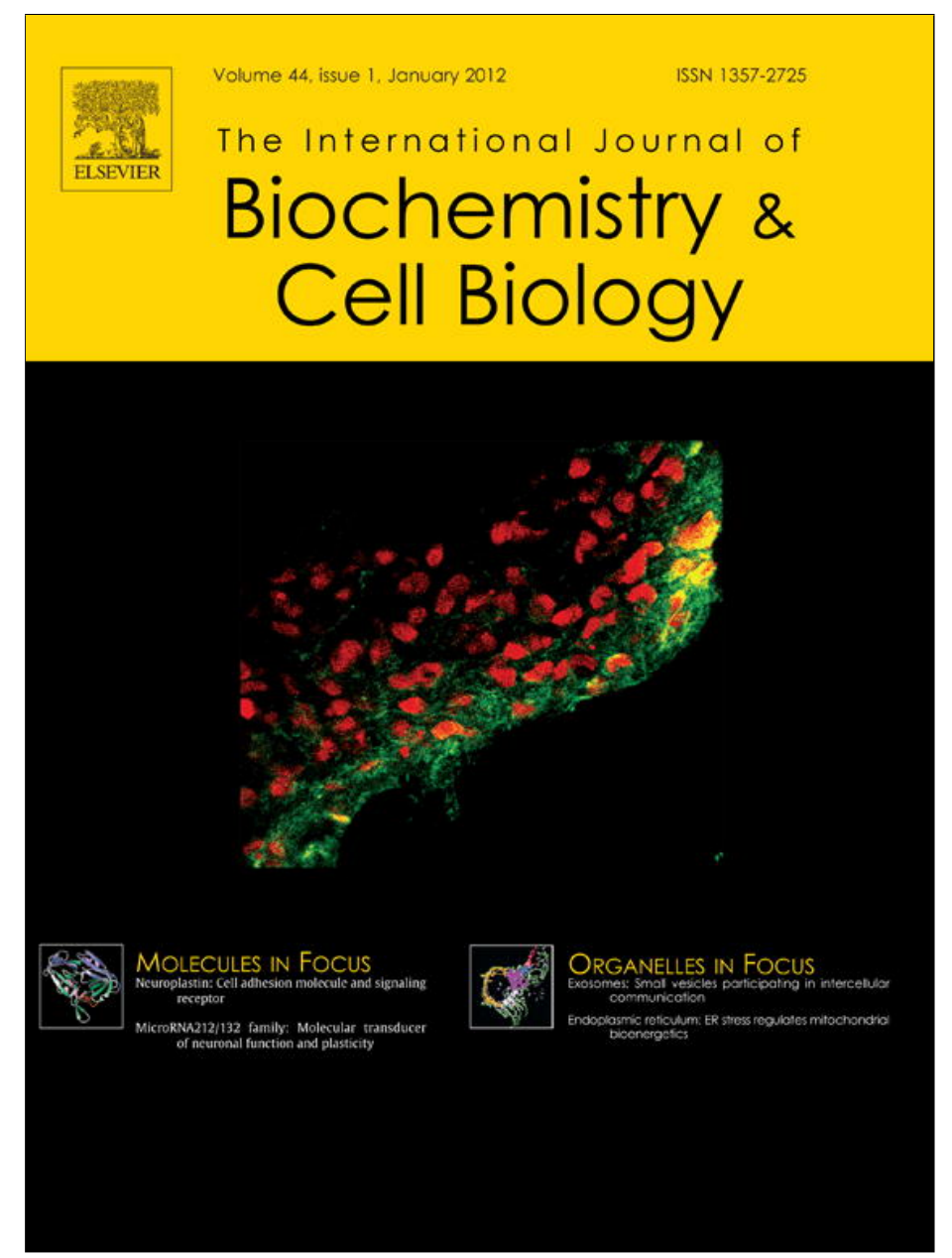

(This is a sample cover image for this issue. The actual cover is not yet available at this time.)

This article appeared in a journal published by Elsevier. The attached copy is furnished to the author for internal non-commercial research and education use, including for instruction at the authors institution and sharing with colleagues.

Other uses, including reproduction and distribution, or selling or licensing copies, or posting to personal, institutional or third party websites are prohibited.

In most cases authors are permitted to post their version of the article (e.g. in Word or Tex form) to their personal website or institutional repository. Authors requiring further information regarding Elsevier's archiving and manuscript policies are encouraged to visit:

http://www.elsevier.com/copyright 


\title{
CA19.9 antigen circulating in the serum of colon cancer patients: Where is it from?
}

\author{
Lydia Mare $^{\mathrm{a}}$, Anna Caretti ${ }^{\mathrm{b}}$, Riccardo Albertini ${ }^{\mathrm{c}}$, Marco Trinchera ${ }^{\mathrm{a}, *}$ \\ a Department of Medicine Clinical and Experimental (DMCS), University of Insubria Medical School, 21100 Varese, Italy \\ ${ }^{\mathrm{b}}$ Department of Health Sciences, San Paolo Hospital, Università degli Studi di Milano, 20142 Milan, Italy \\ c Laboratory of Clinical Chemistry, IRCCS Policlinico San Matteo, P.le Golgi 5, 27100 Pavia, Italy
}

\section{A R T I C L E I N F O}

\section{Article history:}

Received 30 October 2012

Received in revised form 3 December 2012

Accepted 8 January 2013

Available online $\mathrm{xxx}$

\section{Keywords:}

Tumor marker

Colon cancer

Carbohydrate antigen

Hepatobiliary system

Gastrointestinal tract

\begin{abstract}
A B S T R A C T
CA19.9 antigen is a glycoprotein present in human serum and found elevated in various diseases. It is intensively studied since long time as a potential marker for managing cancers of the gastrointestinal tract, but its reliability is widely accepted only for pancreatic cancers. Here, we focused on the tetrasaccharide epitope (NeuAc $\alpha 2-3$ Gal $\beta 1-3[$ Fuc $\alpha 1-4]$ GlcNAc) sialyl-Lewis a studying the biosynthesis, expression, and secretion in colon cancers and related cancer cell lines. We found that the $\beta 1,3$ galactosyltransferase $\beta 3 \mathrm{Gal}-\mathrm{T5}$, responsible for sialyl-Lewis a synthesis, is dramatically reduced in colon adenocarcinomas, in terms of both transcript and enzyme activity levels. Moreover, no or very faint antigen is detectable in colon cancer homogenates, by dot-blot or enzyme immunoassay, while it is commonly evident in sera from different patients. In cancer cell lines synthesizing CA19.9, the amount of antigen secreted is proportional to that expressed on the cell surface, and depends on appreciable levels of $\beta 3 \mathrm{Gal}-\mathrm{T} 5$, which appear much higher than those measured in colon cancer specimens. Since colon cancers appear unable to synthesize relevant amount of CA19.9, we suggest that the antigen circulating in the serum of colon cancer patients may have a different and more complex origin than expected so far.
\end{abstract}

(C) 2013 Elsevier Ltd. All rights reserved.

\section{Introduction}

Sialyl-Lewis a is the tetrasaccharide epitope (NeuAc $\alpha 2-3 \mathrm{Gal} \beta 1-$ $3\left[\right.$ Fuc $\alpha 1-4$ ] GlcNAc) ${ }^{1}$ characterizing the CA19.9 antigen (Magnani et al., 1983; Yue et al., 2011a) present in human serum and found elevated in various diseases (Mann et al., 2000) including cancers of the digestive tract, as pancreas (Ballehaninna and Chamberlain, 2012), bile ducts (Kikkawa et al., 2012), stomach (Kim et al., 2011), and colon (Yamashita and Watanabe, 2009). At present, CA19.9 is recommended by medical societies and study groups for managing cancers of the pancreas but not of the colon (Duffy et al., 2003, 2007, 2010; Locker et al., 2006), but is still widely used in clinical practice, trials, and studies concerning colorectal cancer diagnosis, prognosis, surveillance, and response to therapy (de Haas et al., 2010; Byström et al., 2012; Lin et al., 2012). The existence of such controversial issues and the finding of high CA19.9

\footnotetext{
* Corresponding author at: DMCS, via JH Dunant 5, 21100, Varese, Italy. Tel.: +390332 397 160; fax: +390332397119.

E-mail address: marco.trinchera@uninsubria.it (M. Trinchera).

1 The abbreviations used are: sLea, sialyl-Lewis a, NeuAc $\alpha 2-3$ Gal $\beta 1-3[F u c \alpha 1-$ 4]GlcNAc; sLex, sialyl-Lewis $x$, NeuAc $\alpha 2-3$ Gal $\beta 1-4[$ Fuc $\alpha 1-3]$ GlcNAc; Gal-T, galactosyltransferase; Fuc-TIII, $\alpha 1,3 / 1,4$ fucosyltransferase type III (product of FUT3 gene); EIA, enzyme immunoassay; CEA, carcinoembryonic antigen.
}

in the serum of patients suffering non-malignant diseases (van der Veek et al., 2011), open questions about the biology of such molecule and the rationale of the use as a reliable marker. Little is known about CA19.9 structure, synthesis and secretion in the different tissues, and nothing about the origin of that circulating in health individuals. Recently, it was found that multiple proteins carry the epitope in pancreatic cancer and none appears responsible for cancer up-regulation (Yue et al., 2011b). This may suggest that the synthesis of the carbohydrate epitope is limiting in determining the serum levels. In fact, Narimatsu et al. (1998) reported that FUT3 (Lewis gene) dosage affects CA19.9 positively, while FUT2 (Secretor type $\alpha 1,2$ fucosyltransferase, competing for the synthesis) negatively. In colon cancer, however, among specific glycosyltransferases required for epitope biosynthesis (fucosyltransferase Fuc-TIII, $\alpha 2,3$ sialyltransferases ST3GalIV or ST3GalIII, and $\beta 1,3$ galactosyltransferase $\beta 3 \mathrm{Gal}-\mathrm{T} 5$ ) none is up regulated (Ito et al., 1997; Kudo et al., 1998; Misonou et al., 2009; Dall'Olio et al., 2012). In particular, $\beta 3$ Gal-T5 transcript is expressed in normal colon mucosa but dramatically down-regulated in adenocarcinomas (Salvini et al., 2001; Isshiki et al., 2003; Caretti et al., 2012), confirming the observation that $\beta 1,3 \mathrm{Gal}-\mathrm{T}$ activity is impaired in colon cancers (Seko et al., 1996; Misonou et al., 2009), where type 2 chain oligosaccharides (based on Gal $\beta 1-4$ GlcNAc sequence) predominate over type 1 chain (based on Gal $\beta 1$-3GlcNAc sequence) in various glycoconjugates (Misonou et al., 2009). On this light, the 
concept that CA19.9 is a cancer-associated antigen in human colon appears paradoxical and deserves more investigations.

To address this issue we measured the levels of $\beta 3 \mathrm{Gal}-\mathrm{T} 5$ transcript and $\beta 1,3 \mathrm{Gal}-\mathrm{T}$ activity in bioptic samples pairs from colon adenocarcinomas and surrounding normal mucosa, and determined the amount of sLea antigen expressed in the tissues. We also evaluated in cultured cell lines expressing the antigen their ability to secrete it in the medium. We then compared the obtained data with the amount of antigen detected in control and patient sera.

\section{Materials and methods}

\subsection{Cell cultures}

COLO-205, HCT-15, CACO-2, HT-29 (from human colon adenocarcinomas), and MKN-45 (from human gastric cancer) cells were cultured as previously described (Valli et al., 1998; Salvini et al., 2001). MKN-45 cells expressing Fuc-TIII, named MKN-45-FT, and human pancreatic adenocarcinoma cells BxPC3 and Panc-1, were obtained and cultured as reported (Mare and Trinchera, 2004). CACO- 2 cells differentiated in culture were obtained according to the procedure described (Isshiki et al., 2003).

\subsection{Preparation of human colon samples and cultured cells for analytical procedures}

Human bioptic specimens were collected at surgery, immediately frozen in dry ice and placed in liquid nitrogen until used, as previously reported (Salvini et al., 2001; Caretti et al., 2012). They originated from different parts of the large intestine, including the rectum (samples 3 and 6). Cancers were staged from B2 to C2 (Dukes') and graded from moderately to poorly differentiated. The health mucosa surrounding the cancer lesion in the same surgical resection was referred to as the normal mucosa. For RNA extraction, $1-2 \mathrm{~mm}^{3}$ of frozen material was cut, placed in $0.3 \mathrm{ml}$ of lysis buffer (Ambion RNAqueous minikit, Invitrogen), homogenated with a rotary homogenizer, and processed for total RNA extraction and DNA removal according to the manufacturer's recommendations. For biochemical analysis, $2-3 \mathrm{~mm}^{3}$ of frozen material was cut, carefully rinsed twice in $0.5 \mathrm{ml}$ of ice-cold phosphate buffered saline, placed in $0.5 \mathrm{ml}$ of $0.1 \mathrm{M}$ Tris/ $\mathrm{HCl}$ buffer, $\mathrm{pH}$ 7.5 , and homogenated with a rotary homogenizer. An aliquot of the homogenates was diluted to different protein concentrations and used for dot-blots, another aliquot was made $0.5 \mathrm{mg} / \mathrm{ml}$ Triton X100 and used as the enzyme source for $\beta 1,3 \mathrm{Gal}-\mathrm{T}$ in vitro assay, and a third aliquot was lysated for EIA according to a published procedure (Baeckström et al., 1991). Cultured cells were harvested and freshly processed for flow cytometry as reported (Bardoni et al., 1999; Salvini et al., 2001). For dot-blot, EIA, and enzyme assay, cell pellets were treated as described for bioptic samples but vortexing instead of using the rotary homogenizer.

\subsection{RNA analysis}

For transcript quantification, competitive RT-PCR was performed essentially as previously reported (Trinchera et al., 2011; Caretti et al., 2012). First strand cDNA was prepared for samples and controls in the presence, or omitting, the reverse transcriptase, respectively, and reactions incubated under reported conditions. It was amplified ( $25 \mu \mathrm{l}$ reaction volume) in the presence of $10 \mathrm{fg}$ of competitor for 35 cycles ( $\beta 3 \mathrm{Gal}-\mathrm{T} 5$ ), or $10 \mathrm{pg}$ of competitor for 25 cycles ( $\beta$-actin), under reported conditions. No amplification was detected when the control reactions were used as template. Human $\beta$-actin and $\beta 3 \mathrm{Gal}-\mathrm{T5}$ competitors, and oligonucleotide primers, were those already described (Salvini et al., 2001). Fuc-TIII transcript was quantitated exactly as reported (Trinchera et al., 2011).

\subsection{Enzyme assay}

$\beta 1,3 \mathrm{Gal}-\mathrm{T}$ activity was determined in the reported reaction mixture (Salvini et al., 2001), using 0.6 M GlcNAc as acceptor, in the presence of cell or tissue homogenates at various protein concentrations: $0.5-4.0 \mathrm{mg} / \mathrm{ml}$ for cell lines and clones, $0.5-2.0 \mathrm{mg} / \mathrm{ml}$ for normal colon mucosa, and $5.0-10 \mathrm{mg} / \mathrm{ml}$ for colon cancers. Incubations were done at $37^{\circ} \mathrm{C}$ for 120 (cancers) or $60 \mathrm{~min}$ (all others). At the end of incubation, reaction products were assayed by Dowex chromatography and characterized according to previously reported protocols (Valli et al., 1998). In all cases the reaction product was found to be a disaccharide sensitive to $\beta 1,3$ galactosidase, as expected. In fact, GlcNAc is not used as acceptor by $\beta 1,4$ galactosyltransferases under the reported assay conditions (Valli et al., 1998; Bardoni et al., 1999). One unit of $\beta 1,3 \mathrm{Gal}-\mathrm{T}$ activity corresponds to one nanomole of transferred Gal per $\mathrm{mg}$ of protein homogenate per hour.

\section{5. sLea detection}

Detection of sLea by immunofluorescence and flow cytometry was performed as previously reported (Salvini et al., 2001). For dotblots, aliquots from homogenates, sera, bile, or culture media were applied to the membrane by vacuum aspiration. Serial dilutions of samples were performed in preliminary experiments to set the optimal protein concentrations and amounts needed for detection. Blotting membranes were washed, blocked, stained with primary and peroxidase-labeled secondary antibodies, and visualized by enhanced chemiluminescence as reported for western-blot (Caretti et al., 2012). Monoclonal anti-sLea (from hybridoma 1116-NS-19-9) antibody was prepared as reported (Bardoni et al., 1999). Quantification of CA19.9 in serum and bile samples, in culture media, or in tissue and cell lysates was performed by EIA with an automated analytical system (Cobas Core II, Roche Diagnostics) equipped with dedicated reagents, according to the instructions of the manufacturer.

\section{Results}

3.1. $\beta 1,3 G a l-T$ activity, $\beta 3$ Gal-T5 transcript levels, and sLea expression in normal colon mucosa and adenocarcinomas.

To evaluate the actual ability of colon tissues to synthesize large amounts of sLea, we determined $\beta 3$ Gal-T5 transcript and activity in 9 sample pairs from patient biopsies, each representing colon adenocarcinomas and surrounding normal mucosa. Serum levels of CA19.9 were $115,84.6$, and $19.2 \mathrm{U} / \mathrm{ml}$ in patients 9,8 , and 4 , respectively (normal range $<37 \mathrm{U} / \mathrm{ml}$ ), and not available in the others. Fuc-TIII transcript was found to be heterogeneously expressed in all samples (not shown), as expected (Ito et al., 1997; Salvini et al., 2001; Trinchera et al., 2011).

The amount of $\beta 3 \mathrm{Gal}-\mathrm{T} 5$ transcript expressed in normal colon mucosa is high but variable, ranging from 3 to $20 \mathrm{fg} / \mathrm{pg}$ of $\beta$-actin, and the enzyme activity ranges from 22 to $120 \mathrm{U}$. In cancer samples, $\beta 1$,3Gal-T activity closely follows transcript down-regulation (Fig. 1, panel A, note the different scales used). The calculated reduction is 36.2-folds on average, ranging from a minimum of 6.2-folds in sample 6 to a maximum of 68 -folds in sample 9. Interestingly, in a single adenocarcinoma case (sample 5) where the transcript level is relatively maintained $(0.9 \mathrm{fg} / \mathrm{pg}$ of $\beta$-actin) the enzyme activity reaches the value of $13.2 \mathrm{U}$, while it is lower than $4 \mathrm{U}$ in all other samples. This data indicate that $\beta 3$ Gal-T5 down-regulation in colon cancers leads to extremely low values of enzyme activity. 

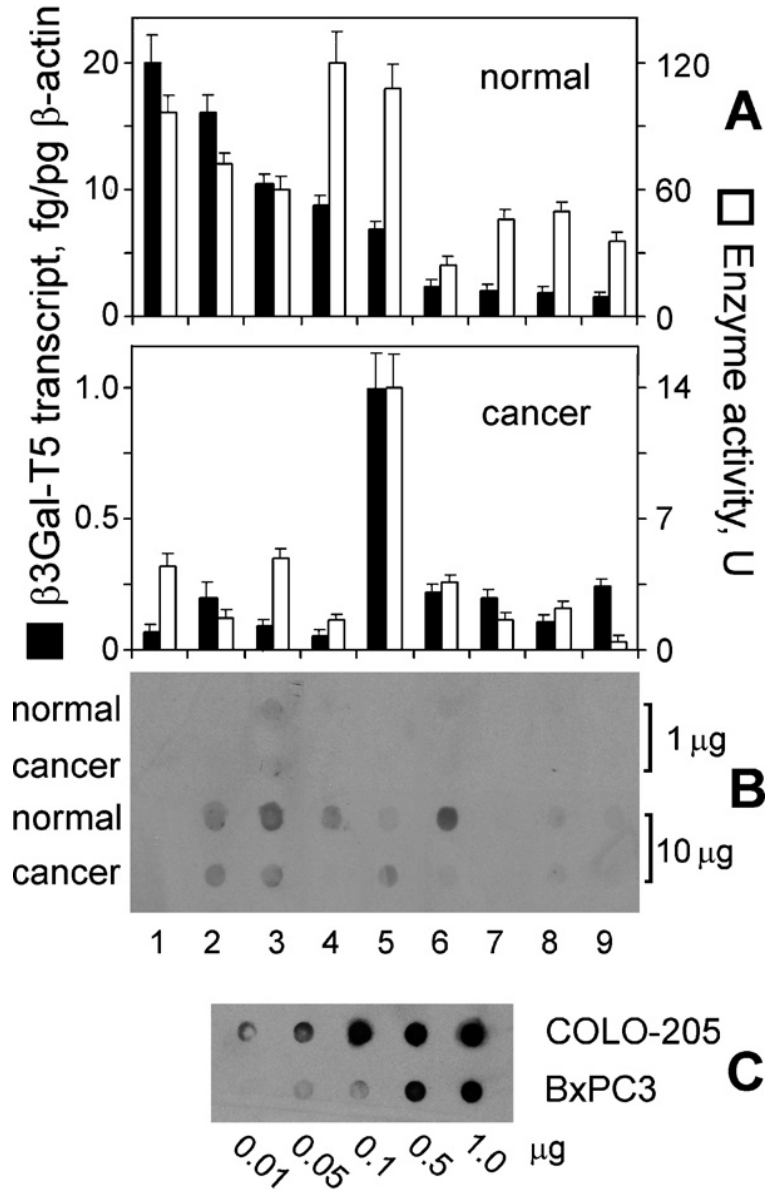

Fig. 1. Expression of $\beta 3 \mathrm{Gal}-\mathrm{T} 5$ and sLea in colon samples from cancer patients. Colon adenocarcinoma and surrounding normal mucosa samples were collected at surgery and immediately frozen. The frozen material was cut in aliquots that were processed for analysis as described under Section 2. (A) $\beta 3$ Gal-T5 transcript (full bars) was quantitated by competitive RT-PCR starting from RNA extracted from an aliquot of frozen samples, and $\beta 1,3 \mathrm{Gal}-\mathrm{T}$ activity (empty bars) was determined by in vitro assay using homogenates prepared from a second aliquot of the frozen samples. Results are the mean \pm standard deviation for three determinations. Note the different scales used. (B) sLea was determined by immunostaining of dot-blots prepared with two amounts of sample homogenates brought to the same final volume, using anti-sLea monoclonal antibody followed by peroxidase-labeled secondary antibody. (C) Different dilutions of the homogenates prepared from two cell lines expressing the antigen were blotted and stained for reference under identical conditions. Labels show the actual amount of sample protein blotted.

To directly evaluate the synthesis of sLea in the tissues, sample homogenates were analyzed through immunostaining of dot-blots. Surprisingly, under conditions used for detection in cell lines, sLea is undetectable in both normal colon mucosa and adenocarcinomas (Fig. 1, panels B and C). Using much more protein in the blots, sLea is detected in many normal mucosa specimens and faintly in few cancers, but remains undetectable in others. To better assess the actual amount of CA19.9 expressed in colon tissues with respect to cell lines, we measured CA19.9 by EIA in tissue and cell lysates. Such assay linearly detects CA19.9 in COLO-205 and BxPC3 lysates starting from 5.0 and $10.0 \mu \mathrm{g} / \mathrm{ml}$ of cell protein, respectively, while none is detected using up to $40.0 \mu \mathrm{g} / \mathrm{ml}$ of protein lysate from HCT-15, a cell line known to lack sLea (Fig. 2, lower panel). Using $20.0 \mu \mathrm{g} / \mathrm{ml}$ of protein from colon tissue lysates, CA19.9 is detected at very low levels in one adenocarcinoma and one normal mucosa sample, and remains undistinguishable from the background (value detected in HCT-15 cells) in all other samples (Fig. 2, upper panel). These findings demonstrate that no accumulation of sLea occurs in colon adenocarcinomas.

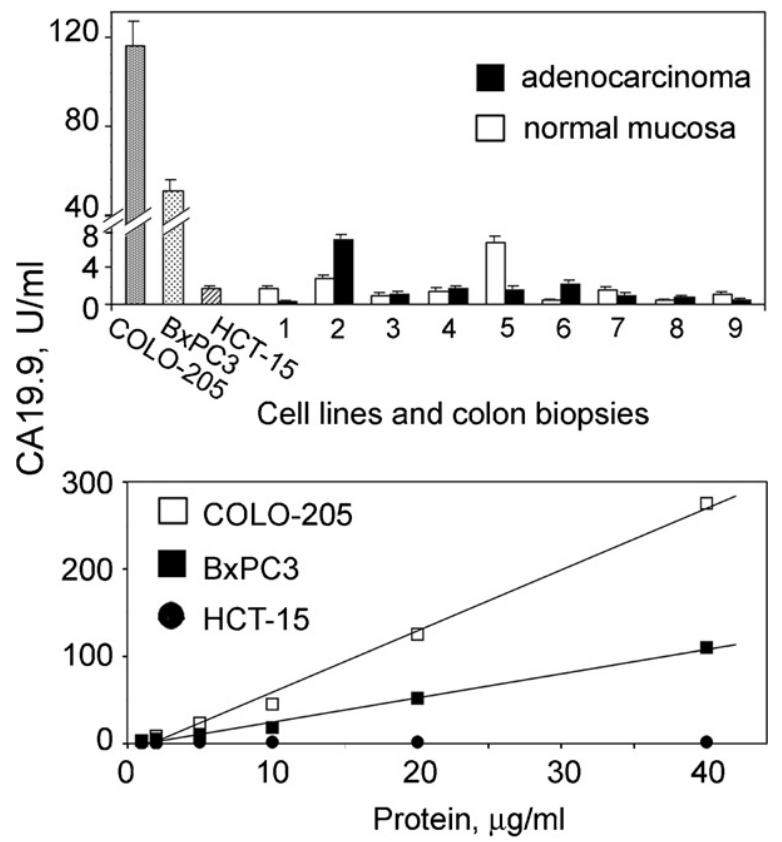

Fig. 2. Detection of CA19.9 by EIA in lysates from colon biopsies and cultured cell lines. Cultured cells and colon biopsies were processed for analysis as described under Section 2. Lower panel, serial dilutions of cell lysates were assayed by EIA. Upper panel, lysates from the indicated cell lines and from colon biopsies (numbered as in Fig. 1) were diluted to a protein concentration of $20 \mu \mathrm{g} / \mathrm{ml}$ and assayed by EIA. Results are the mean \pm standard deviation for three determinations.

\subsection{Expression and secretion of sLea in cultured cell lines}

As a model for studying sLea secretion, we evaluated in cultured cell lines the relationship between sLea secreted in the culture medium and expressed on the cell surface, since cancer cell lines secrete mucin-type glycoproteins carrying the epitope (Baeckström et al., 1991, 1995). To this purpose, a set of cancer cell lines from the digestive tract expressing different amount of antigens were selected in preliminary experiments. They were plated at the same density and cultured for $48 \mathrm{~h}$. The amount of sLea present on the surface was then quantitated by immunofluorescence and flow cytometry, while that accumulated in the culture medium was detected by dot-blot immunostaining and quantitated by EIA (Fig. 3). Among colon adenocarcinoma cell lines, COLO-205 cells, expressing very much sLea on the surface, secrete large amount of antigen in the medium, while CACO-2 and HT-29, expressing low amount of sLea on the surface, secrete minimal amount of antigen, as detected by both dot-blot immunostaining and EIA. Moreover, all cell lines lacking expression on the surface, as HCT-15, Panc-1, and MKN-45, do not secrete detectable antigen at all. In addition, CACO2 cells differentiated in culture and expressing about three times more $\beta 1,3 \mathrm{Gal}-\mathrm{T}$ activity than undifferentiated cells, also express more sLea on the surface and secrete more sLea in the medium. On the other side, BxPC3 cells (from pancreas) expressing intermediate amount of sLea on the surface, and MKN-45-FT (from stomach), a recombinant clone forced to express sLea on the surface through over-expression of Fuc-TIII, secrete a moderate amount of antigen in the medium as detected by dot-blot immunostaining, but EIA detects much more antigen in the culture medium of BxPC3. Altogether these data indicate that secretion of CA19.9 antigen in cancer cell lines does not occur in the absence of concurrent expression on the surface, and only cells expressing $\beta 3 \mathrm{Gal}-\mathrm{T} 5$ are able to secrete relevant amounts of antigen. Interestingly, there is a very good correlation between the amounts of antigen expressed on the surface and secreted in the culture medium of colon cancer 


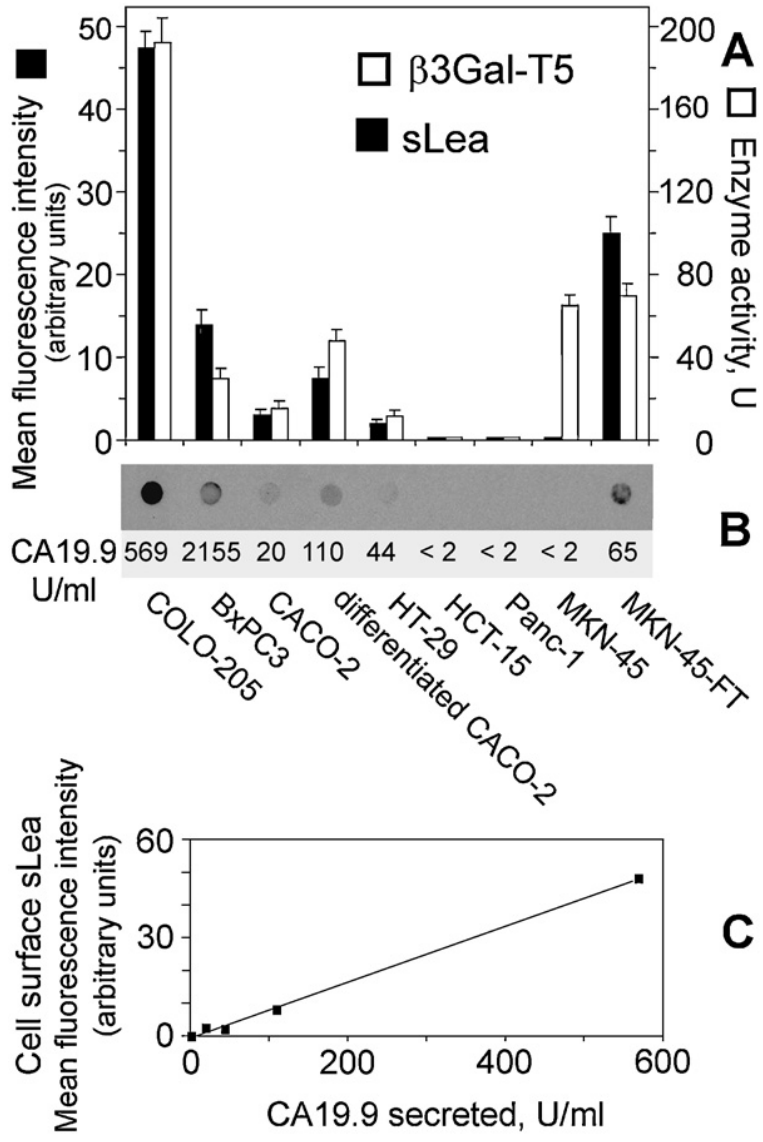

Fig. 3. Expression on the surface and secretion in the culture medium of sLea synthesized in different cell lines. Different cell lines were seeded at the same density, cultured for $48 \mathrm{~h}$, harvested, and analyzed together with the culture media as detailed under Section 2. (A) sLea antigen expressed on the cell surface (full bars) was determined by immunostaining and flow cytometry performed on a fresh aliquot of the cell pellet. $\beta 1,3 \mathrm{Gal}-\mathrm{T}$ activity (empty bars) was determined by in vitro assay as in Fig. 1. Results are the mean \pm standard deviation for three determinations. (B) sLea secreted in the culture media was detected by immunostaining of dot-blots obtained with $50 \mu \mathrm{l}$ of culture media, or quantitated by EIA. Numbers are the mean for three determinations; standard deviations were less than $15 \%$. (C) Correlation between sLea measured on the surface (by flow cytometry) and CA19.9 secreted in the culture media (quantitated by EIA) of colon cancer cell lines (HCT-15, CACO-2, HT-29, differentiated CACO-2 and COLO-205). Input data were from panel B. Correlation coefficient is 0.998 as determined by linear regression.

cells (Fig. 3C), while those from pancreas or stomach seem to have different behavior (Fig. 3C).

Noteworthy, $\beta 1,3$ Gal-T activity measured in CACO- 2 and HT29 cells is 15.2 and $11.4 \mathrm{U}$, respectively. Such values, able to direct only minimal secretion of antigen, are still 7- to 22-folds larger than those measured in cancers patients 8 and 9 of Fig. 1A, whose serum CA19.9 is indeed above the cut-off level.

\subsection{Detection of sLea in the serum}

Unfortunately, we lack serum samples from the same patients where the biopsies are from. As an alternative, we checked samples from individuals whose serum levels of CA19.9 cover a wide range. Fig. 4 shows that CA19.9 is very easily detected by dot-blot immunostaining, even blotting minimal volumes of sera having low antigen amounts measured by EIA. This indicates that the blotting procedure is highly sensitive and that at least some immunogenic properties of CA19.9 present in tissues, cells, and sera are similar. On the other side, the quantitative relationship between EIA and blotting detection in cancer patient serum and in the bile is

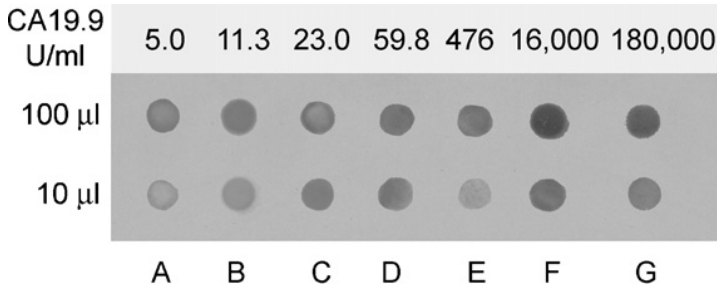

Fig. 4. Detection of CA19.9 in patient serum and in the bile. The amounts of serum or bile indicated were brought to the same volume, blotted, and stained with anti-sLea antibody as in Fig. 1. EIA quantification in the samples is shown at the top of the panel. Numbers are the mean for three determinations; standard deviations were less than $15 \%$. $A-F$ " are the serum samples indicated in the following lines: $A$ is from a health control, B, E, and F from cancer patients, C from a chronic alcoholic, and D from a chronic $\mathrm{C}$ virus hepatitis patient. $\mathrm{G}$ is a bile sample, collected at cholecystectomy, that was diluted ten-times before blotting or assaying.

very poor, as found in the culture medium of BxPC3 cells. Such discrepancy probably accounts for the structural heterogeneity of the antigen, already proved to occur among different biological sources but even within the same one (Baeckström et al., 1991, 1994, 1995; Yue et al., 2011a, 2011b). At this regard, it is interesting to note that CA19.9 circulating in the serum of cancer patients or present in the bile is better detected by EIA than by blotting, while that found in colon biopsies or colon-derived cell membranes and culture media is not.

\section{Discussion}

We found that the synthesis and secretion of CA19.9 antigen in colon cancer presents several problems not supposed so far. In fact we found that $\beta 3 \mathrm{Gal}-\mathrm{T} 5$, the enzyme responsible for one of the glycosylation steps necessary for epitope synthesis, is so strongly down-regulated in colon cancers that drops down to values far below those needed to synthesize the antigen in cell lines. Furthermore, the antigen is not detectable in the cancer biopsies, or more difficult to detect than in the normal mucosa. Since in colon cancer cell lines the amount of antigen secreted in the culture medium is proportional to that expressed on the cell surface, our data open the question if colon cancers are able to secrete large amounts of sLea.

In previous studies, sLea was found in some colon cancers analyzed by histochemistry (Ito et al., 1997; Kudo et al., 1998) or sporadically distributed in some parts of the tumor (Tabuchi et al., 1988), but western blot and histochemical data were not overlapping (Kudo et al., 1998). On the light of our present data, we suggest that such discrepancies reflect the degree of blood contamination in the tissues, or depend on binding to the cell membrane of the antigen carried by the blood. In fact, we found that patient serum is very easily stained by anti-sLea antibody, so that $0.01 \mathrm{ml}$ of serum seem to contain more sLea than some tens or even hundreds of milligrams of colon cancer tissue. Moreover, studies performed on colon cancer at surgery (Tabuchi et al., 1988; Nakagoe et al., 2000) showed that CEA and sLex, but not CA19.9, are more elevated in the blood from vessels draining the tumor region than in peripheral blood, with spikes coincident with surgery manipulation. Since CEA (Maxwell, 1999) and sLex (Trinchera et al., 2011) are actually synthesized by colon cancer cells, these in vivo results corroborate the data that we obtained in cultured cell lines. It would be very interesting in the future to validate such data in vivo comparing antigen levels in cancer biopsies and serum samples from the same patient. At this stage, we speculate that the metabolic origin of circulating CA19.9 should be searched in other tissues actually able to synthesize and secrete relevant amounts of antigen. Normal intestinal mucosa is a potential candidate, due to the high expression levels of glycosyltransferases as $\beta 3 \mathrm{Gal}-\mathrm{T} 5$ and 
Fuc-TIII. However, it does not accumulate large quantities of antigen under basal conditions, probably because several additional factors, unknown at present, control CA19.9 synthesis and secretion in vivo, and any of them may be triggered by the cancer lesion. The biliary tract is also a candidate, because an amazing huge amounts of CA19.9 (millions of $\mathrm{U} / \mathrm{ml}$ ) is present in the bile, as reported (Baeckström et al., 1994) and confirmed in our experiments. However, a mechanism allowing CA19.9 elevation without jaundice needs to be envisaged in this case. Anyway, our data are compatible with the observation that appreciable levels of CA19.9 are commonly detected in healthy individuals (the source of which remains totally unknown), and elevated levels, including extremely high levels, occur in several benign conditions affecting the hepatobiliary system (Mann et al., 2000; Akdoğan et al., 2001; van der Veek et al., 2011).

CA19.9 circulating in cancer patients was originally reported as an high molecular weight mucin (size above $5.0 \times 10^{6} \mathrm{Da}$ )(Magnani et al., 1983), perhaps difficult to immobilize on blotting membranes. It is also predictable that such molecules bear several epitopes all recognized by EIA but not by dot-blot immunostaining. We speculate that CA19.9 sources providing low-moderate dot-blot staining but high titer by EIA, as the culture medium of pancreatic BxPC3 cells, the bile, and the blood from some cancer patients ( $\mathrm{E}$ and $\mathrm{F}$ in Fig. 4), do contain a high molecular weight form of the antigen, while the others do not. They include the culture medium from colon cancer cell lines and cell lysates from colon cell lines and biopsies, where dot-blot immunostaining correlates with EIA. Accordingly, the main molecules carrying CA19.9 in the culture medium of COLO-205 cells were identified as CD-43 glycoforms (Baeckström et al., 1995), 150-300 kDa in size, expected to easily bind blotting membranes. The molecular size heterogeneity of CA19.9 (Yue et al., 2011a) may be helpful in the future in the attempt to identify the actual source of circulating antigen, an information that we believe necessary to answer several clinical questions.

\section{Acknowledgments}

This work was supported by grants from MIUR and from the University of Insubria to MT.

\section{References}

Akdoğan M, Saşmaz N, Kayhan B, Biyikoğlu I, Dişibeyaz S, Sahin B. Extraordinarily elevated CA19-9 in benign conditions: a case report and review of the literature. Tumori 2001;87:337-9.

Baeckström D, Hansson GC, Nilsson O, Johansson C, Gendler SJ, Lindholm L. Purification and characterization of a membrane-bound and a secreted mucin-type glycoprotein carrying the carcinoma-associated sialyl-Lea epitope on distinct core proteins. Journal of Biological Chemistry 1991;266:21537-47.

Baeckström D, Karlsson N, Hansson GC. Purification and characterization of sialyl-Le(a)-carrying mucins of human bile; evidence for the presence of MUC1 and MUC3 apoproteins. Journal of Biological Chemistry 1994;269: 14430-7.

Baeckström D, Zhang K, Asker N, Rüetschi U, Ek M, Hansson GC. Expression of the leukocyte-associated sialoglycoprotein CD43 by a colon carcinoma cell line. Journal of Biological Chemistry 1995;270:13688-92.

Ballehaninna UK, Chamberlain RS. The clinical utility of serum CA 19-9 in the diagnosis, prognosis and management of pancreatic adenocarcinoma: an evidence based appraisal. Journal of Gastrointestinal Oncology 2012;3:105-19.

Bardoni A, Valli M, Trinchera M. Differential expression of beta1,3galactosyltransferases in human colon cells derived from adenocarcinomas or normal mucosa. FEBS Letters 1999;451:75-80.

Byström P, Berglund A, Nygren P, Wernroth L, Johansson B, Larsson A, Glimelius B. Evaluation of predictive markers for patients with advanced colorectal cancer. Acta Oncologica 2012;51:849-59.

Caretti A, Sirchia SM, Tabano S, Zulueta A, Dall'Olio F, Trinchera M. DNA methylation and histone modifications modulate the $\beta 1,3$ galactosyltransferase $\beta 3 \mathrm{Gal}-\mathrm{T} 5$ native promoter in cancer cells. International Journal of Biochemistry \& Cell Biology 2012;44:84-90.

Dall'Olio F, Malagolini N, Trinchera M, Chiricolo M. Mechanisms of cancerassociated glycosylation changes. Frontiers in Bioscience 2012;17: 670-99. de Haas RJ, Wicherts DA, Flores E, Ducreux M, Lévi F, Paule B, et al. Tumor marker evolution: comparison with imaging for assessment of response to chemotherapy in patients with colorectal liver metastases. Annals of Surgical Oncology 2010;17:1010-23.

Duffy MJ, van Dalen A, Haglund C, Hansson L, Klapdor R, Lamerz R, et al. Clinical utility of biochemical markers in colorectal cancer: European Group on Tumour Markers (EGTM) guidelines. European Journal of Cancer 2003;39: 718-27.

Duffy MJ, van Dalen A, Haglund C, Hansson L, Holinski-Feder E, Klapdor R, et al. Tumour markers in colorectal cancer: European Group on Tumour Markers (EGTM) guidelines for clinical use. European Journal of Cancer 2007; $43: 1348-60$.

Duffy MJ, Sturgeon C, Lamerz R, Haglund C, Holubec VL, Klapdor R, et al. Tumor markers in pancreatic cancer: a European Group on Tumor Markers (EGTM) status report. Annals of Oncology 2010;21:441-7.

Isshiki S, Kudo T, Nishihara S, Ikehara Y, Togayachi A, Furuya A, et al. Lewis type antigen synthase (beta3Gal-T5) is transcriptionally regulated by homeoproteins. Journal of Biological Chemistry 2003;278:36611-20.

Ito $\mathrm{H}$, Hiraiwa $\mathrm{N}$, Sawada-Kasugai $\mathrm{M}$, Akamatsu $\mathrm{S}$, Tachikawa T, Kasai $\mathrm{Y}$, et al. Altered mRNA expression of specific molecular species of fucosyl- and sialyltransferases in human colorectal cancer tissues. International Journal of Cancer 1997;71:556-64.

Kikkawa S, Sogawa K, Satoh M, Umemura H, Kodera Y, Matsushita K, et al. Identification of a novel biomarker for biliary tract cancer using matrix-assisted lase desorption/ionization time-of-flight mass spectrometry. International Journal of Proteomics 2012;2012:108609.

Kim DH, Oh SJ, Oh CA, Choi MG, Noh JH, Sohn TS, et al. The relationships between perioperative CEA, CA 19-9, and CA 72-4 and recurrence in gastric cancer patients after curative radical gastrectomy. Journal of Surgical Oncology 2011;104:585-91.

Kudo T, Ikehara Y, Togayachi A, Morozumi K, Watanabe M, Nakamura M, et al Up-regulation of a set of glycosyltransferase genes in human colorectal cancer. Laboratory Investigation 1998;78:797-811.

Lin PC, Lin JK, Lin CC, Wang HS, Yang SH, Jiang JK, et al. Carbohydrate antigen 19-9 is a valuable prognostic factor in colorectal cancer patients with normal levels of carcinoembryonic antigen and may help predict lung metastasis. Internationa Journal of Colorectal Disease 2012;27:1333-8.

Locker GY, Hamilton S, Harris J, Jessup JM, Kemeny N, Macdonald JS, et al. ASCO. ASCO 2006 update of recommendations for the use of tumor markers in gastrointestinal cancer. Journal of Clinical Oncology 2006;24:5313-27.

Magnani JL, Steplewski Z, Koprowski H, Ginsburg V. Identification of the gastrointestinal and pancreatic cancer-associated antigen detected by monoclonal antibody 19-9 in the sera of patients as a mucin. Cancer Research 1983;43:5489-92.

Mann DV, Edwards R, Ho S. Lau WY, and Glazer G. Elevated tumour marker CA19-9: clinical interpretation and influence of obstructive jaundice. European Journal of Surgical Oncology 2000;26:474-9.

Mare L, Trinchera M. Suppression of $\beta$ 1,3galactosyltransferase $\beta 3$ Gal-T5 in cancer cells reduces sialyl-Lewis a and enhances poly $\mathrm{N}$-acetyllactosamines and sialyl-Lewis x on O-glycans. European Journal of Biochemistry 2004;271: 186-94.

Maxwell P. Carcinoembryonic antigen: cell adhesion molecule and useful diagnostic marker. British Journal of Biomedical Science 1999:209-14.

Misonou Y, Shida K, Korekane H, Seki Y, Noura S, Ohue M, Miyamoto Y. Comprehensive clinico-glycomic study of 16 colorectal cancer specimens: elucidation of aberrant glycosylation and its mechanistic causes in colorectal cancer cells. Journal of Proteome Research 2009;8:2990-3005.

Nakagoe T, Sawai T, Tsuji T, Jibiki M, Ohbatake M, Nanashima A, et al. Differences in release mechanisms and distributions for sialyl Le(a) and sialyl $\mathrm{Le}(\mathrm{x})$ antigens in colorectal cancer. Annals of Surgical Oncology 2000;7 289-95.

Narimatsu H, Iwasaki H, Nakayama F, Ikehara Y, Kudo T, Nishihara S, et al. Lewis and secretor gene dosages affect CA19-9 and DU-PAN-2 serum levels in normal individuals and colorectal cancer patients. Cancer Res 1998;58:512-8.

Salvini R, Bardoni A, Valli M, Trinchera M. Beta 1,3-Galactosyltransferase beta 3 Gal-T5 acts on the GlcNAcbeta $1 \rightarrow 3$ Galbeta $1 \rightarrow 4$ GlcNAcbeta $1 \rightarrow R$ sugar chains of carcinoembryonic antigen and other $\mathrm{N}$-linked glycoproteins and is down-regulated in colon adenocarcinomas. Journal of Biological Chemistry 2001;276:3564-73.

Seko A Ohkura T, Kitamura $H$, Yonezawa S, Sato E, Yamashita K. Quantitative differences in GlcNAc: beta $1 \rightarrow 3$ and GlcNAc:beta $1 \rightarrow 4$ galactosyltransferase activities between human colonic adenocarcinomas and normal colonic mucosa. Cancer Research 1996;56:3468-73.

Tabuchi Y, Deguchi H, Saitoh Y. Carcinoembryonic antigen and carbohydrate antigen 19-9 levels of peripheral and draining venous blood in colorectal cancer patients. Correlation with histopathologic and immunohistochemical variables. Cancer 1988;62:1605-13.

Trinchera M, Malagolini N, Chiricolo M, Santini D, Minni F, Caretti A, Dall'olio F. The biosynthesis of the selectin-ligand sialyl Lewis $\mathrm{x}$ in colorectal cancer tissues is regulated by fucosyltransferase VI and can be inhibited by an RNA interference-based approach. International Journal of Biochemistry and Cell Biology 2011;43:130-9.

Valli M, Gallanti A, Bozzaro S, Trinchera M. Beta-1,3-galactosyltransferase and alpha-1,2-fucosyltransferase involved in the biosynthesis of type-1-chain carbohydrate antigens in human colon adenocarcinoma cell lines. European Journal of Biochemistry 1998;256:494-501. 
van der Veek PP, de Vos Tot Nederveen Cappel WH, Langers AM, van Hoek B. Two patients with extremely elevated tumor markers: where is the malignancy? Gastroenterology Research and Practice 2011;2011:123743.

Yamashita K, Watanabe $\mathrm{M}$. Clinical significance of tumor markers and an emerging perspective on colorectal cancer. Cancer Science 2009;100: $195-9$.
Yue T, Maupin KA, Fallon B, Li L, Partyka K, Anderson MA et al. Enhanced discrimination of malignant from benign pancreatic disease by measuring the CA 19-9 antigen on specific protein carriers. PLoS ONE 2011a;6:e29180.

Yue T, Partyka K, Maupin KA, Hurley M, Andrews P, Kaul K, et al. Identification of blood-protein carriers of the CA 19-9 antigen and characterization of prevalence in pancreatic diseases. Proteomics 2011b;11:3665-74. 